\title{
BELLEZA Y LEGITIMACIÓN DEL ARTE CONTEMPORÁNEO (REFLEXIONES A PARTIR DE ARTHUR C. DANTO)
}

Francisco J. Falero Folgoso

Universitat de les Illes Balears

Data recepción: 2019-02-26

Data aceptación: 2020-03-11

Contacto autor: fj.falero@uib.es

ORCID: https://orcid.org/0000-0002-4406-3981

\section{RESUMEN}

La categoría estética de la belleza ha sido marginada, cuando no totalmente reprobada, por las poéticas y las teorías artísticas durante el siglo XX. Dicha categoría habría sido vista como una rémora desarrollando así actitudes francamente beligerantes. En la última década del siglo ha sido de nuevo objeto de atención por parte de la reflexión del mundo artístico, en parte como culminación de una reacción frente al denominado arte contemporáneo, poniéndose de manifiesto en programas curatoriales, en ensayos así como en respuesta a los abusos comerciales del patrimonio por parte del turismo cultural. En este trabajo reflexionaremos sobre el valor y significación de esta categoría hoy a partir de la obra del filósofo Arthur Danto, para llegar a apuestas hermenéuticas como las de Federico Vercellone o Stefano Zecchi, o de la teoría crítica de Byung-Chul Han, pasando la crítica de la tutela de Salvatore Settis.

Palabras clave: belleza, estética, vanguardia, arte contemporáneo, crítica de arte

\section{ABSTRACT}

During the 20th century the aesthetic category of beauty was marginalized, if not wholly condemned, by art theory. It was regarded as a hindrance by the leading avant-garde trends of the day, opposed as they were to the ideals of art or to its social function and developing belligerent attitudes in the process. In the last decade of the century, however, it came under renewed attention from art research, partly as a reaction to so-called "contemporary art". This can be seem in some curatorial programmes and research works, and in the response to the commercial abuses suffered by art heritage at the hands of cultural tourism. In this paper we reflect on the present-day meaning and value of this category, based on the work of the philosopher Arthur Danto, while also considering concepts such as the aesthetic hermeneutics of Federico Vercellone and Stefano Zecchi, the critical theory of Byung-Chul Han, and the cultural criticism of Salvatore Settis.

Keywords: beauty, aesthetic, avantgarde, contemporary art, art criticism

Partamos de las consideraciones del crítico y filósofo del arte Arthur C. Danto, punto de referencia de estas reflexiones, según el cual, jugando con la traducción inglesa del famoso verso de Rimbaud, "Un soir, j'ai assis la Beauté sur mes genoux. Et je l'ai trouvée amère. Et je l'ai injuriée"
(Danto 2005, 70)', se ha abusado y se abusa hoy de la categoría estética de la belleza en la definición del arte.

La problemática se inserta en toda una corriente de pensamiento de revisión crítica del arte contemporáneo que puede tomar muy bien su punto 
de partida en la obra de Jean Clair en los primeros años ochenta del siglo pasado (Clair 1983). Fue el punto de partida que dio inicio a toda una virulenta polémica, especialmente en Francia, sobre la legitimación del ahora denominado como arte contemporáneo entre partidarios y detractores alcanzando su cenit en la siguiente década, cuyo primer balance puso de manifiesto Yves Michaud (Michaud 2015). En este contexto, refiere Danto que en Estados Unidos a partir de la publicación de un ensayo del prestigioso crítico Dave Hickey en 1993 (Hickey 2012) se emprende toda una tendencia de la crítica de la década que pretendía situar como leitmotiv en la reflexión del arte el problema de la belleza, tras décadas de consenso en torno a su obsolescencia filosófica en el mundo del arte. La cuestión se planteaba como reacción en una coyuntura que atravesaba un intenso periodo de activismo político del arte alcanzando su apogeo en la Bienal Whitney de 1993 (Danto 2005, 43-44). Este es el motivo que da pie a las reflexiones, que podríamos denominar de contra reacción, de Danto sobre el tema que culminan en la publicación de la obra a la que nos estamos refiriendo. Por tanto, el libro de Danto, aunque muy contextualizado, se inscribe en ese movimiento de reflexión que se desarrolla hasta nuestros días, de un lado a otro del Atlántico, en toda una serie de ensayos de distinta índole que partiendo del mundo del arte se extienden a ámbitos estéticos más extensivos. Señalemos a este respecto, a modo de ejemplo entre otros muchos de los cuales algunos citaremos más adelante, en el desarrollo de las argumentaciones, el elocuente cambio de título llevado a cabo con motivo de la reedición de la obra de Luc Ferry Homo aestheticus, por Le sens du Beau. Aux les origines de la culture contemporaine (Ferry 2017). Se volvía a una reposición de la "actualidad de lo bello" como rezaba la obra de Gadamer que ya a contracorriente publicaba a mediados de los años setenta y que significativamente sólo fue traducida al castellano a principios de los noventa (Gadamer 1991).

Los planteamientos del problema en torno a las antinómicas relaciones entre belleza y arte del siglo XX han sido bien señalados por Federico Vercellone. Veamos. Afirma rotundamente al comienzo de su ensayo: "Por lo pronto, no hay belleza en el siglo XX. En el fondo, este siglo más bien ha experimentado su ausencia" (Vercellone 2013, 17). Y plantea las siguientes cuestiones: ¿está dotado el siglo XX de un ideal propio de belleza? ¿O se trata, sin embargo, que vive en violento enfrentamiento con la belleza, que no quiere contemplarla más y renuncia a delimitarla en el cosmos de sus propios valores? (...) ¿Nos encontramos, entonces, ante un siglo sobrio, que no muestra interés por la belleza y prescinde de ella a favor de la funcionalidad y lo útil?" (VerceIlone 2013, 18-19). La respuesta de Vercellone es que, en efecto, el concepto constructivo de arte derivado de la conversión de la estética dieciochesca, kantiana, en filosofía (histórica) del arte por el romanticismo conllevaba inevitablemente a este desenlace de divorcio en el siglo veinte iniciado con las vanguardias. No hay ninguna posibilidad de albergar un ideal de belleza porque el romanticismo supuso el desequilibrio entre la finalidad-sin-fin del juico estético y la finalidad técnica de la naturaleza del juicio teleológico, en beneficio del segundo, respecto a la comprensión del arte. Una semilla inoculada especialmente desde las reflexiones de Schlegel que aparecen ya en la primera "Introducción" a la Crítica del Juicio de Kant de las Philosophische Lehrjahre (Los años de aprendizaje filosófico) que, madurándose a lo largo del siglo XIX, acabaría de brotar con todas sus consecuencias con las vanguardias, provocando la antítesis entre belleza y (arte del) siglo XX. Se habría llegado, después de un siglo volcado hacia la filosofía del arte en detrimento de la estética natural, al rechazo de todos los cánones de lo bello, visto con total desconfianza, para lanzarse a los brazos de su opuesto ideal lógico, lo feo. La filosofía del arte desarrollada durante el siglo XIX es aquella que ha despojado lo bello natural, como correlato de lo bello metafísico, para instaurar en su lugar un bello propiamente artístico, un bello susceptible de construirse técnicamente. $Y$ así llega Vercellone a preguntarse: "y si la belleza, justamente al hacerse artística (...) abdicase de sí misma y encontrase en lo feo su propio camino?" y responde: "Es cuanto ocurre precisamente en el siglo XIX bajo el signo de la bohème artística, que trae consigo, en realidad, lo más contradictorio que pueda darse: la propuesta del arte como institución autónoma." (Vercellone 2013, 44). 
Ni que decir tiene que Vercellone persigue finalmente, a través de sus análisis, hacer un alegato por la reinstauración de la belleza en el provenir del arte, en última instancia una legitimación estético-clásica del arte. Pero dejémoslo aquí por ahora y retomemos el hilo central con Danto, con quien habíamos comenzado, y veamos cuál es su postura respecto de estas cuestiones planteadas por el filósofo italiano y con qué argumentaciones la sostiene -avanzado ya que se encuentra en las antípodas- el arte queda auto-legitimado en su propia autonomía filosófica. Lo cual no es nada de extrañar dado la diferenciación acusada de sus principios, hermenéuticos, en el primer caso, analíticos, en el segundo.

En principio, hay coincidencia digamos de descripción de síntomas sobre el siglo XX. Danto se dirige directamente hacia al núcleo de la que él denomina "Vanguardia intratable" y pone el acento citando el manifiesto dadaísta de Tristan Tzara de julio de 1918: "Queda por hacer un gran trabajo negativo de destrucción. Tenemos que barrer y limpiar." (Danto 2005, 90). Y de ahí la diatriba contra la belleza, ese loco e incontenible deseo de asesinarla, como proclamaría Tzara. Belleza y siglo XX quedan así en una relación antitética. Danto señala, entonces, algo verdaderamente importante y que explica la escisión de Dadá como "Vanguardia intratable", con una lógica distinta respecto del resto de las vanguardias. Dice así:

El dadá se resiste a que se lo consideren bello: ésa es su gran trascendencia filosófica frente al discurso tranquilizador según el cual, con el paso del tiempo, lo que había sido rechazado como arte por no ser bello acabaría cobrando carta de naturaleza como bello y sería reivindicado como arte. Puede que esto sucediera realmente con el arte de vanguardia del siglo XIX y principios del XX. Matisse, por ejemplo, pasó a ser para muchos paradigma de belleza, como les pasó a los impresionistas, tan denostados en su tiempo. En cambio, el dadá me parece el paradigma de lo que yo denomino Vanguardia intratable, cuyos productos sólo por error pueden considerarse bellos. No es ése su objetivo, ni aspira a eso (Danto 2005, 91).

Podríamos leer entonces que el dadaísmo es la culminación efectiva, incontrovertible, objetiva, de la lógica romántico-bohème que refería Vercellone. Es, sin embargo, sólo mera apariencia, la lógica interna de ambos discursos es diametralmente diferente. Pero dejémoslo en suspenso y vayamos a otra coincidencia de auscultación. Me refiero a ese otro punto culminante del rechazo explícito de la belleza a lo largo del siglo XX a la que ambos otorgan un punto determinante en el transcurso de sus respectivas argumentaciones. Me refiero, pues, a la postura del Expresionismo Abstracto norteamericano. Ambos citan el mismo fragmento extraído del texto "The Sublime is Now", de Barnett Newman (Newman 2006, 214218) referente a la conocida afirmación de que la invención de la belleza por los griegos como un ideal ha supuesto la pesadilla para el arte y el pensamiento filosófico de la estética europea. En definitiva, la expresión del Absoluto es sublime, según manifiesta la poética de Expresionismo Abstracto, frente al modelo de una belleza sublime del ideal de perfección de la tradición europea. En definitiva, romanticismo frente a clasicismo.

Coincidencia en la auscultación, pero diferencia de diagnóstico que revelan estrategias enfrentadas: el impulso del arte moderno de destruir la belleza que pregonara Newman implica para Danto una vía franqueable, un paso más para la total liberación del arte y su constitución filosóficamente autónoma. En Vercellone, es un punto extremo de retorno. La explicación de la figura y obra de Warhol se revela determinante entonces en ambas estrategias como veremos más adelante. Digámoslo en una palabra, Vercellone busca una legitimación estética, en su sentido prístino de aisthesis, del arte, Danto su superación por una legitimación conceptual del arte. Es decir, ambos se sitúan en uno de los polos de la dicotomía que señalara Odo Marquard entre estético y anestético (Marquard 1994, 21-35). La filosofía de Vercellone quiere mantenerse en el arte estético, la de Danto va hacia el arte anestético. El sublime, por tanto, es considerado par el filósofo italiano como una disolución estética de la forma que habría que corregir históricamente, mientras que para el filósofo americano en cambio es el punto histórico último antes del advenimiento de la disolución de lo estético histórico mismo. La bohème para Danto desemboca en el sublime del Expresionismo Abstracto americano porque, aun con todo, la recusación de la belleza por este último sigue siendo un movimiento estético. La 
"Vanguardia intratable" es decisivamente antiestética, se desvincula de toda emotividad subjetiva. La obra de arte se desentiende de toda forma de relación simbólica y adquiere pleno valor de signo. Para una lectura como la de Vercellone, el gesto iconoclasta de Dadá es un avatar más, todo lo extremo y significativo que sea, en ese itinerario de la disolución de la forma.

Pero dejemos ahora a Vercellone, quien nos ha valido como punto de diálogo, y centrémonos en la estrategia de Danto. Como es harto conocido, y reiterado en sus diferentes ensayos (Danto 2002), el punto nodal de su filosofía del arte viene marcado por la toma de conciencia ante la indiferenciación formal de una obra como Caja BriIlo de Andy Warhol respecto de su referente, obra que se constituye en paradigma para construir un concepto objetivo del arte. Este gesto es, con una estrategia totalmente diferente, muy similar en el fondo al que no mucho tiempo después llevará a cabo un filósofo tan en las antípodas como Alain Badiou, al pretender fundamentar precisamente la legitimación del arte contemporáneo con una nueva vía alternativa a la estética que él denomina con un sorprendente neologismo: la "inestética" (Badiou 1998). En este caso Badiou se vale de Mallarmé que lo convierte en el artista paradigma de todo arte posible. $Y$ digo con gesto similar porque el punto de partida de su indagación filosófica es señalar la invalidación de la estética como filosofía del arte ante el despliegue del fenómeno del arte contemporáneo cuya característica es justamente ser antiestético. Pero aquí el alcance y resultado son complemente diferentes a los de Danto. Para decirlo brevemente, en Badiou el triunfo es del arte sobre la filosofía al contrario que en Danto. Como lo expresa Mehdi Belhaj Kacem: "La inesthétique est la possibilité que la philosophie se fonde à nouveau elle-même, c'est-à-dire comme Système, sous la condition moderne de l'art comme déconstruction de l'esthétique" (Kacem 2010, 19). Esta, sin duda, no es la ambición de Danto sino, antes al contrario, que la filosofía conceptual logre por fin definir el arte frente al escepticismo de otras apuestas analíticas como la de George Dickie por ejemplo. Así pues, frente a la inhibición o impotencia de la filosofía como estética ante el arte, su definitivo divorcio, Danto reivindica la soberanía de una filosofía antiestética del arte. La "inestética", por su parte, se somete al arte y pretende levantar un sistema filosófico del campo de ruinas en que la práctica del arte contemporáneo ha dejado la estética. No es éste el lugar, y escapa a nuestra finalidad, para analizar las consideraciones críticas de Medih Belahi a Badiou, sin embargo en el texto se presentan observaciones que son de sumo interés aquí. En este sentido, señala M. Belahi:

Je crois ensuite qu'il y a une raison à l'impossibilité, pour une philosophie moderne, de produire une esthétique -une raison que Badiou n'énonce pas comme telle-; c'est la suivante: depuis Duchamp [...] et Dada, pour la plupart des " gens-de-l'art » (au sens des « beaux-arts »), la philosophie de l'art, l'esthétique classique, voit sa condition de possibilité court-circuitée par le fait que la catégorie central de l'esthétique, de Platon à Hegel en passant par Kant, c'est la beauté. C'est la catégorie du Beau. C'est là-dessus qu'est fondée toute esthétique; or, I'art contemporain au sens strict, autrement dit les beaux-arts aujourd'hui, se targuent le plus souvent, et presque en primer lieu, d'être tout sauf «beaux». Ils présentent la plupart du temps des procédures plus ou moins sophistiquées de mise en déroute de la catégorie de beauté, et donc de toute esthétique au sens classique. Là où l'esthétique, qui culmine avec Hegel, est en effet toujours une architecture de placement hiérarchique des arts sous le paradigme du beau, l'art, au moins depuis Duchamp, est une maligne déconstruction des hiérarchies instituées par l'autorité philosophique comme esthétique. [...] l'art contemporaine est l'assomption négative de l'effondrement architectonique de l'esthétique, et n'a aucun besoin de la philosophie pour le tenir à bout de bras sa tâche infinie de déconstruction de l'esthétique (Kacem 2010, 11-12).

A partir de aquí, del "adiós a la estética", tal como la ha proclamado Jean-Marie Schaeffer (Schaeffer 2005), sólo cabe un discurso como Crítica (sofisticada) del arte singularizado, sin parangón de género ni de artista a artista e incluso, en última instancia, de la obra en su singularidad categórica; o como objeto de la Sociología cuantitativa del arte, tal como la ha desarrollado Nathalie Heinich en Francia (Heinich 1998). En otros términos, la eliminación de todo rastro axiológico. Danto es consciente de ello y asume los hechos, pero se resiste a disolver la filosofía en sociología. De hecho ejerce una destacada la- 
bor como crítico de arte vinculada a su trabajo filosófico. La particularidad de Danto a este respecto es que frente a los deconstructores de la estética que se centran en la liquidación de Hegel, en una secuencia que va del romanticismo, con Kant como precedente, a Heidegger (Schaeffer 1992), el filósofo norteamericano reivindica su figura y su estética la sitúa en el núcleo de su investigación.

La estrategia de Danto es clara y circunstanciada dentro del panorama artístico norteamericano. La legitimación por parte de la crítica de arte de la obra de Warhol, y en general de todo el Pop Art, pasaba indefectiblemente por desarticular la crítica que sustentaba el Expresionismo Abstracto americano, en tanto en cuanto suponía la apoteosis de la pintura y la abstracción como su culminación bajo la categoría del sublime. La base de esta crítica formalista estaba encabezada en América por Clement Greenberg. Esta crítica tiene en Kant su referente estético y Danto encuentra en Hegel su aliado frente a Kant en este panorama crítico americano. En otros términos, supone situar el debate crítico en la antinomia formalismo/contenidismo. Pero para llevar a cabo esta refutación se vale de una interpretación, digamos, antihegeliana de Hegel, que a su vez se enfrenta a una interpretación igualmente antikantiana de Kant.

En la estrategia político-estética desplegada por Danto el punto focal de este proceso se sitúa en la crítica del movimiento estético inglés representado por el círculo de Bloomsbury. El filósofo moral Georges E. Moore y el crítico de arte Roger Fry constituyen sus principales referentes a este respecto. Lo que les reprocha es su moralismo estético, que él denomina impropiamente esteticismo. Evidentemente éste se retrotrae a la sociedad victoriana de mediados del siglo XIX en su figura clave, John Ruskin. Lo que viene a argumentar Danto es precisamente que el abuso (del uso) de la belleza por parte del arte llevado a cabo por esta religión de lo bello conduciría con toda lógica, y con razón, a abusar (injuriarla) de la belleza en los inicios de los movimientos de vanguardia. Todo ello ha conducido a una tergiversación de la filosofía del arte como una estética política de la belleza. Así se vio cómo en la posguerra se dieron vinculaciones ilegítimas entre movimientos de vanguardia y comunismo, entre radicalismo artístico y político, en la sociedad conservadora americana. Todo el esfuerzo de Danto, por tanto, va dirigido a deshacer el vínculo establecido por la modernidad entre arte y belleza, las «bellas artes», que implica desvincularlo de la moral en tanto en cuanto la modernidad estética anglosajona ha establecido un vínculo asimismo entre belleza y moral que ha determinado el mundo y el pensamiento artísticos en la segunda mitad del siglo XIX y sus prolongaciones en el XX. Es aquí que la "Vanguardia intratable", es decir, Dadá y más concretamente Duchamp, cumple un papel histórico decisivo en el avance del análisis filosófico. De tal manera que afirma:

De no haber sido, por ejemplo, por las vanguardias artísticas del siglo XX, casi con toda certeza los filósofos seguirían enseñando que el vínculo entre arte y belleza es conceptualmente riguroso. Hizo falta la energía de las vanguardias artísticas para abrir una brecha entre el arte y la belleza que antes habría resultado impensable, y que [...] siguió siendo impensable hasta mucho después de abrirse esta brecha, en buena parte porque se consideraba que el vínculo entre arte y belleza poseía la fuerza de una necesidad a priori (Danto 2005, 68).

En este sentido, Danto verá en Warhol la clave de apertura de la posibilidad de desarticular definitivamente este error estético debido a un malentendido filosófico que él habría logrado poner al descubierto.

El crítico Roger Fry, y con él los modernos de Bloomsbury, habrían sido así víctimas de este error estético al juzgar las obras de los postimpresionistas en las primeras décadas del siglo XX, al considerar no sólo, con ser grave, que la pintura era cuestión de imitación de la naturaleza sino fundamentalmente porque supusieron que la finalidad de la misma era ser una manifestación de la belleza. Así, si bien es justa una apreciación estética respecto a la revalorización de los objetos rituales de los pueblos africanos o de otros pueblos primitivos como obras de arte, se ven conducidos a un error conceptual al fundamentarla en su virtual belleza que el crítico se esfuerza por hacer perceptible, como igualmente ocurría con los cuadros fauvistas de Matisse, por ejemplo. La belleza es difícil, como vendría a decir Sócrates al final del Hipias Mayor, y las obras de arte se 
verían feas hasta que el crítico no diera con la vía de ver la belleza en el arte, una crítica concebida como el ejercicio paciente de un saber ver, máxima del formalismo, según el silogismo: si el objeto como producto de hacer humano es bello, es una obra arte. Y esta postura llega hasta Clement Greenberg quien señalaría, a este respecto, que todo arte verdaderamente original se vería al inicio como feo. Deshacer semejante silogismo, desmontar el a priori, es lo que según Danto lleva a cabo la "Vanguardia intratable" en su vertiente paradigmática de Dadá, cuya irreverente poética conllevará a que sus "[...] productos sólo por error puedan considerarse bellos"; lo cual supone "[...] su gran trascendencia filosófica frente al discurso tranquilizador según el cual, con el paso del tiempo, lo que había sido rechazado como arte por no ser bello acabaría cobrando carta de naturaleza como bello y sería reivindicado como arte" (Danto 2005, 91). Y, en efecto, Dadá alcanza este paroxismo en el arte al rebasar el límite de lo estético, a saber, la representación o la nuda presentación de lo repugnante. Aquello que es irreductible según la tesis de Kant a toda satisfacción estética. La legitimación de obras como las de un Damien Hirst en el panorama del arte contemporáneo sería muestra inequívoca de la asunción y triunfo del dadaísmo, expresado en esas poéticas de lo repugnante (y lo abyecto), sobre las estéticas dieciochescas. Afirma Danto que Kant habría visto la idea misma de un "arte repulsivo" como una contradicción en sus propios términos dado que, según su presupuesto, el arte tiene como propósito el de producir placer. Así que, interpretando a Kant, afirma: "[...] si una obra de mímesis representaba algo repulsivo, sería en sí repulsiva, contraviniendo su estatuto artístico, que por naturaleza aspira a complacer" (Danto 2005, 94). El trasfondo del análisis Danto a propósito de la estética kantiana se articula entonces para desvirtuar en su fuente la crítica formalista anglosajona. Por ello justamente se refiere al límite que en el interior de la propia teoría de Kant cortocircuita el proceso de estetización de un objeto en su representación. Un límite infranqueable en el que el procedimiento de la crítica formalista de la transformación de la percepción de lo bello es irreductible: neutraliza el discurso de la redención estética (Danto 2005, 91). En efecto, esto es lo que Kant viene a es- tablecer en parágrafo 48 de la Crítica del Juicio (Kant 1990, 267-269), que se retrotrae en última instancia a un aspecto fundamental de la teoría de la mímesis de Aristóteles, según expone en el capítulo IV de la Poética². Un límite antropológico pues que invalida la argumentación de una belleza temporalmente incomprendida, una estética en diferido, que sostenía aquella crítica.

Pero convendría, a este respecto, recordar cómo Konrad P. Liessmann señala la aporía estetizante que supone caer en la red conceptual de Kant para las poéticas artísticas de la Modernidad que neutraliza el carácter intratable designado por Danto:

Los intentos de ciertos artistas de romper este círculo y provocar con su arte precisamente asco y repugnancia,son por consiguiente más que equívocos, pues el llamado entendido en arte reacciona con un enjuiciamiento de la calidad estética, es decir, no reacciona como se había deseado. Y precisamente aquel que ante tal provocación reacciona con repugnancia -es decir, según la intención del artista, que quería provocares tildado demasiado a menudo de inculto $y$ enemigo del arte. Tal vez, de Kant podamos seguir aprendiendo que el juicio estético de hecho funciona y tiene que funcionar sin interés alguno, y que todos los intentos de engendrar mediante arte, algo distinto, como por ejemplo el asco, pero también consternación, tienen que caer en el vacío (Liessmann 2006, 32-33).

Lo que viene a decirse es que paradójicamente el arte moderno actuando contra Kant no ha hecho más que superar al propio Kant reafirmando su mismo razonamiento. Dicho de otro modo, el Kant empírico, contextualizado por el gusto en las postrimerías del siglo XVIII, queda superado por el Kant filósofo del juicio de gusto: lo que se planteó como una limitación antropológica no resultó ser finalmente, tras el desarrollo de la "Vanguardia intratable", más que una limitación histórica.

Habría que considerar, no obstante, que el problema proviene sin duda de la lectura sesgada de la estética de kantiana que establece Danto. Ante todo, porque parece hacer caso omiso a la distinción entre lo agradable y lo bello propiamente dicho y centra su interpretación sobre la identificación de una y otra categoría, dando lu- 
gar a una visión puramente hedonista de la estética en Kant y ello tergiversa su teoría, siendo en todo caso, como afirmó Adorno (Adorno 1980, 22), un "hedonismo castrado". La explicación de la elección de lo repulsivo y abyecto por la «vanguardia intratable» frente a lo bello y sus consecuencias no debería partir simplemente desde el nivel puramente psicológico de la satisfacción perceptiva. Con ello evidentemente Danto quiere poner de manifiesto el firme carácter antiestético del estatuto artístico de dichas poéticas. Pero quizá en este sentido el propio Kant era antiestético. En todo caso, insistimos, lo bello no es reductible a lo agradable como desde luego Kant lo expresa de manera manifiesta en el parágrafo 44 (Kant 1990, 250-260).

El problema del desinterés es decisivo porque es el fundamento en Kant de la libertad. Un arte agradable a la sensibilidad supone una determinación de los fines de los sentidos. Bello significa pues libre de la constricción de los intereses de los sentidos. Así pues, cuando Danto habla del concepto de belleza no significa lo mismo que para Kant. Y por ello mismo para este último la belleza es símbolo de la moralidad: la libertad de imaginación análoga a libertad de la razón, como rezaba el parágrafo 59. Evidentemente Danto señala este fundamental aspecto y es entonces cuando procede a rechazar la otra vertiente de la crítica anglosajona: la función social del arte. En este sentido, señala cómo para el círculo de Bloomsbury, siguiendo los principios de Moore, el nexo entre belleza, bondad y arte es inextricable, de manera tal que perseguir la belleza a través del arte adquiría el significado de moralizar el mundo. Un programa de civilización estética en el que "...no andaban tan lejos de Kant, a tenor de la conclusión a la que llega éste, a saber, que la belleza es símbolo de la moral, si bien en su caso la relación era una suerte de analogía" (Danto 2005,88 ). Sin embargo, la apostilla con que acaba el párrafo no es en absoluto secundaria, como parce deducirse del hilo de sus argumentaciones en este aspecto, porque realmente lo que señalaría es que no es tanto con Kant sino con Schiller con quien estarían más próximos; aunque la vinculación de una utopía estética en la modernidad es de una compleja genealogía como se puede ver en Filiberto Menna (Menna 2001).
Así pues, a lo que pone fin el gesto de Duchamp (por ejemplo, poniendo bigotes a la Gioconda) es a la convicción de la salvación del mundo no por el arte sino por lo bello. Un arte antiestético, es decir, desagradable era la condición para redimir el arte de la subyugación a la falsedad a la que lo tenía sometido el complaciente mundo de la sociedad victoriana y eduardiana. Es pues un giro político de denuncia de alienación de la realidad por las élites burguesas. La gran conflagración bélica llevaría a un punto insostenible aquel credo del embellecimiento (ocultamiento) de la realidad: el horror era tan descomunal (sublime) que lo derrumbó. En el entramado argumentativo de Danto cumple así un papel nodal de la visión teleológica en la liberación del concepto de arte. Un arte que sigue siendo moral, de denuncia cívica, abre los contenidos materiales del arte a lo inhumano, lo abyecto, siguiendo así la estela del moralismo estético/artístico desde Ruskin: el arte no solamente puede ser sino que debe ser no bello, anti-bello, para ser moral, es inmoral que siga siendo estético; o es un imperativo moral que los artistas no pueden hacer obras de arte bellas para una sociedad inmoral. Siguiendo esta huella se legitimarían obras como la performance (registrada en video) titulada Bossy Burguer (1991) de Paul McCarty, no porque sean de una belleza insólita, como señala Danto que recibió la crítica de su momento prolongado el imperativo de Bloomsbury y por lo tanto moralmente provechosa la para la sociedad, sino porque su poética es moralmente bella; sería bello hacer un uso de lo repugnante con fines morales del bien social: la denuncia de los estereotipados cánones sociales y la obesidad de la sociedad de consumo. Y señala que esto puede leerse como un ejemplo de la hipotiposis kantiana, malinterpretando, a mi juicio, el parágrafo 59 de la Crítica del Juicio, porque supone en última instancia reintroducir la heteronomía estética en un sentido que no es sino una expresión más del paradigma del moralismo estético de origen pitagórico-platónico tal como Armando Plebe lo determinó (Plebe 1961, 2).

De este modo, Danto plantea una dialéctica histórica de la modernidad. Porque a partir de aquí critica a Kant siguiendo a Hegel. La modernidad afirma la belleza (moral) del arte (de Kant al formalismo), luego la niega en (nombre de) la moralidad (de la vanguardia dadaísta al activismo) 
y finalmente la sintetiza (la supera moralmente) omnicomprensivamente en el concepto lógico del arte (la filosofía analítica). Hay un final (lógico) del arte. La belleza es pues "finalmente" una opción más de las posibilidades del arte, conviviendo pacíficamente, sin contradicción, con lo repugnante o abyecto y otros sentimientos o emociones en cuanto posibles contenidos estéticos objetivos vehiculados por la obra de arte. Como ocurre con Kant, el Hegel de Danto es "antihegeliano". Si respecto del primero lo bello queda limitado de facto a lo agradable, respecto de Hegel lo bello no es una categoría dialéctica del Espíritu (la manifestación sensible de lo absoluto o la idea), sino un contenido mental (de lo que piensa y lo que siente) del sujeto, o dicho de otra forma una inversión psicológica: "[... ] si la belleza se percibe como un modulador en arte, entonces la maravillosa idea hegeliana -«La belleza artística nace y renace del espíritu»- se entiende a la perfección. Va de la mente del artista a la del espectador a través de los sentidos" (Danto 2005, 177). De este modo una concepción metafísica del arte es reconducida a una cognitiva del arte. Por lo demás, según señala T. Griffero, este proceso de reinterpretación tergiversada de Hegel tiene su origen entre sus propios epígonos, como se puede apreciar en la teoría estética de Friedrich Th. Vischer: "[...] dal momento che l'idea è ora ritenuta irrealizzabile e ben presto soppiantata da un più generico "contenuto de vita", la bellezza artistica si reduce a mero effetto di superficie ("impressione d'insieme") senza alcun corrispettivo interiore" (Griffero 1998, 82). De ahí que la considere como un modulador (junto a lo repugnante o la indignación) en la producción de la intencionalidad de la obra de arte, aquello que hace posible el éxito del significado de la obra, es decir, tiene un papel funcional interno en la obra de arte, no externo: la función social. A partir de estas constataciones, siguiendo el tema de este trabajo, lo que nos interesa no es desarrollar un análisis de la lectura de Hegel y Kant por parte de Danto, sino ver cómo se materializa esta teoría respecto de la cuestión de la legitimación crítica del arte. De este modo, viene a argumentar el valor de la belleza en el seno del Expresionismo Abstracto.

Bajo la interpretación política maniquea de Clement Greenberg, según nos cuenta Danto (Danto 2005, 205), la belleza queda subsumida en el kitsch bajo el fascismo y el sublime se erige expresión de la vanguardia socialista, que llevaría a Barnett Newman a concebir el destino histórico del arte como una continua querella entre tendencias formalizadoras e informalizadoras. El informalismo sería, podríamos decir por tanto, el kunstwollen del moderno, frente a la perfecta forma del kunstwollen clásico que, anacrónico, se convierte en vehículo estético de la ideología del fascismo. En otros términos, en la poética del Expresionismo Abstracto el sublime reemplaza a la belleza como fin esencial del arte. El problema entonces se desplaza a esta categoría limitadora del concepto de arte, constituyendo el mayor desafío para la belleza. El procedimiento metodológico es similar, partiendo del concepto kantiano, pasando por Burke y Lyotard, desemboca en una lectura contraria a Kant. En esta ocasión desciende lo sublime del ámbito de lo trascendental a mero contenido del asombro en la conciencia del sujeto, es decir, una sensación. Con ello no sólo desarticula el principio fundamental de un kunstwollen moderno plasmado en las obras del Expresionismo Abstracto, sino que la propia poética sea determinable como sublime. Así no es la consecución teleológica de la forma pura que se auto-expresa indiferente a un contenido referencial de una exterioridad a sí misma: el espíritu subjetivo que se hace presente desbordando todo límite formal, su representatividad como imagen. Pero ni siquiera la característica que lo define, es decir, que se pueda determinar como el vehículo de un contenido asombroso, en este caso la transmisión de una sensación de lo maravilloso de la plena conciencia de lo irrepresentable e ininteligible en lo exterior, la naturaleza, e interior, el ser racional del hombre. Por consiguiente, respecto al primer aspecto, analizando el cuadro Onement I de Newman, llega a la conclusión de que "La pintura abstracta no está desprovista de contenido. Lo que hace es permitir la presentación de un contenido sin los límites de la representación en imágenes. Por ello, desde el principio, los inventores de la abstracción creyeron [la cursiva es mía] que ésta estaba dotada de una realidad espiritual." (Danto 2005, 220). Entonces lo sublime como contenido —-sensación en la mente de asombro- puede ser el rasgo principal de esta poética pero no definitorio o excluyente respecto de otras cualidades estéticas, o moduladores, como precisamente la belleza. 
Porque lo bello puede ser causa de asombro y de ahí que haya procedido a eliminar el sentimiento de terror como elemento necesario en la definición del sublime que en la lógica de su argumentación contradiría lo bello (Danto 2005, 217-218). Este es el caso de la relectura de la serie de Elegy for the Spanish Republic de otro de los destacados representantes del Expresionismo, Robert Motherwell, que es a la vez sublime y bello o sublime en tanto que bello.

En efecto, el análisis de la belleza estética en las imágenes no figurativas de la serie no se centra en la determinación de los elementos empíricos que la caracterizan, sino que la belleza de dichas obras se deduce de la conexión conceptual con el tema, esto es, la melancolía. De manera que, aun teniendo los cuadros de Motherwell una significación política, "Su patente belleza derivaba naturalmente del hecho de ser elegías, puesto que las elegías deben ser bellas por naturaleza. A nuestro juicio, la belleza de la elegía transforma de algún modo el dolor en algo soportable" (Danto 2005, 49). La belleza es pues interna y por ello "No hay que admirar los cuadros por ser bellos, sino porque el que lo sean está internamente vinculado con el referente y su modalidad" (Danto 2005, 164). Es decir, la belleza como modulador expresivo, su carácter agradable que incita a la calma, es adecuado al tema conceptual de la obra. Lo que se valora en la obra y la legitima no es la belleza, sino la adecuación a los fines significativos de la obra: la reacción ante los sucesos de la Guerra Civil y el derrocamiento de la república española, visto desde la distancia, no podría ser otra que la elegíaca y de ahí su belleza. Una belleza que nos capta inmediatamente, como confiesa (Danto 2005, 153), que requiere de tu atención, pero que sólo el análisis conceptual permite otorgarle su valor relativo, es decir, como modulador adecuado. Como se advierte, pese a que había sostenido que la belleza no era un requisito para el arte, la noción de "belleza interna" que desarrolla en el capítulo 4 parece indicar una matización de su postura anterior. En efecto, la belleza se convierte en determinadas obras en condición interna, intrínseca, de su determinación conceptual como obra de arte. Cabe, en todo caso, resaltar la argumentación del parágrafo al respecto, dónde la inconsistencia de lo bello queda manifiesta al determinarse sin más como un sentimiento semejante a "...la repugnancia, el erotismo, la sublimidad, además de la piedad y el terror...", es decir su psicologización. Por otra parte, no deja de ser curioso que habiendo desautorizado la metafísica kantiana de la visión de lo bello, con su determinación de una "belleza interna" al concepto de arte en determinadas obras, al final se filtre de alguna manera la diferenciación de Kant entre belleza libre y belleza adherente. Porque en cierto modo podría leerse "interna" como "adherida". Y además es llamativo el que en determinados casos, ".... sin saber por qué nada más verla e intuitivamente [Las Elegías por la República española] que era algo por lo que valía la pena pararse" (Danto $2005,153)$ sea la modalidad de percatación de lo bello en el arte. Uno se pregunta, si lo bello es evidente como sentimiento de la estructura universal antropológica, entonces la sensación de admiración inmediata de bello ante la serie de Motherwell sería tan inmediata para un espectador medio como lo es la sensación al ver el arco iris, según su propia argumentación. Me temo que, ante la obra, la intuición que le llevó a detenerse no fue en cuanto especie humana impresionable ante la belleza natural sino como crítico especializado dispuesto a priori a ver allí una obra de arte y luego a posteriori justificarla intelectualmente. De manera que, efectivamente, puede que después de su argumentación mucha gente a quien pasara hasta ese momento desapercibida su belleza esté en disposición de apreciarla "intuitivamente" en estas obras y en otras que le parezcan similares. En cualquier caso, el sublime de la representación abstracta de la muerte, el final trágico de la república española, requería del tono elegíaco, de ahí la belleza de la serie, la representación de la muerte de un bello ideal político.

Una vez considerada la belleza aceptable en un concepto de arte, no como representación mimética de la belleza natural, sino en cuanto interna y funcional respecto de su significado, porque ni es superada por lo sublime abstracto, ni es antitética como en la injuria de la Vanguardia intratable, lo importante es saber cuándo es legítimo valerse de la belleza en el arte y cuándo un abuso. Entonces vemos que el criterio no es justamente autónomo sino heterónomo, la crítica estética es dependiente del criterio moral. Porque 
"[...] es un error presentar como bello lo que clama, sino la acción, sí al menos a la indignación" (Danto 2005, 166). En este sentido, es un acierto en el caso de las Spanish Elegies haber hecho uso de la belleza. Pero no lo hubiera sido en el caso de El Guernica, por ejemplo, porque la inmediatez de los hechos no se adecúa a una actitud contemplativa de reflexión sobre la muerte, sino que requieren la implicación. El modulador en este caso es la indignación y Picasso, modulando su mensaje político a través de su obra mediante este grito de sentimiento de rabia acertó, de ahí su gran valor. Igualmente que en una obra como el Vietnam Veterans' Memorial en Washington de 1982 el uso de la belleza esté justificado, como consuelo o duelo de un suceso irremediable, pero no en el caso, por ejemplo, de las hermosas fotografías de Sebastião Salgado dónde, la cruda realidad coetánea queda embellecida, mostrando una disonancia entre la belleza exhibida y el contenido de dolor y sufrimiento ahí innecesario, que requieren moralmente la acción o la retórica de la indignación. En definitiva, para Danto la belleza, considerada empíricamente sensual, implica el goce y como tal es inmoral su modulación en toda producción de obras de arte que pretendan enmascarar la fealdad del mundo. Pero incluso en aquéllas ajenas al cinismo y la hipocresía se trataría de un error al introducir un elemento distorsionador del mensaje, provocando una falla en su significación. Por ello frente a la crítica radical heredera de los postulados de la "Vanguardia intratable" que deslegitiman todo uso de la belleza cabe la opción de la belleza, pero no al arbitrio del artista, sino lógicamente fundamentada en la adecuación expresiva de la significación intrínseca de la obra. En el marco de las tendencias del activismo político de finales de XX, Danto encuentra una legitimación cognitiva y moral para la belleza: el consuelo. Un consuelo que explicaría que la obra del período de Niza de Matisse no queda desvalorizada por su ilegitima barroca belleza, según la crítica vanguardista, sino que ésta, en cuanto goce estético, es un modulador interno adecuado a la significación de la obra como consuelo. Y se pregunta Danto ante la pertinencia de una poética que busca la construcción de una torre de marfil, de un santuario dónde le sufrimiento queda excluido: "Pero ¿qué hay de malo en crear un espacio de belleza en un mundo tan cruel? Nada, sólo es un gesto profundamente humano de paliar el sufrimiento inexorable de la vida en el que la belleza es un bálsamo, como en las Elegías, supone un distanciamiento de la realidad" (Danto 2005, 169).

Las reflexiones estéticas de Danto se enmarcan tras la conmoción de los atentados de New York de 11 de septiembre, cuando obtiene la "...prueba de que la belleza en los momentos extremos de la vida está profundamente arraigada en lo humano" (Danto 2005, 51) y el arte ante acontecimientos tan descomunales recurre a la belleza para encarnar adecuadamente el sentimiento de tristeza, monumentos fúnebres dónde consolar el alma humana.

Visto en perspectiva, esta revalorización del esteticismo vinculado a situaciones consolatorias viene a inscribirse como un capítulo subsiguiente de la historia de la belleza melancólica, como lo Otro inalcanzable, de la que Winckelmann, al final de su Historia del Arte en la Antigüedad nos ofrece la imagen como la figura del hombre amado que parece percibir una mujer enamorada entre lágrimas en la vela del barco que ve alejarse desde la orilla sin esperanza de retorno (Winckelmann 2011, 194). Una figura melancólica que a través de Baudelaire, De Chirico, etc., marcan la modernidad. La crítica de arte bajo la filosofía analítica de Danto conduce a esta visión de la belleza estetizante marginal en el arte.

Precisamente la revocación del carácter nostálgico de la belleza en la modernidad (y en la posmodernidad) es la tentativa de Vercellone desde una perspectiva hermenéutica y no hedonista. Ambos coinciden en proponer la belleza como valor fundamental en la vida o en la existencia del hombre frente a la deconstrucción y denigración que han impuesto las tendencias vanguardistas del siglo XX sin la cual el mundo es insoportable. como posibilidad de procurar un hábitat agradable, placentero; o como posibilidad de un hábitat interpretable, comprensible.

En la tesis del filósofo italiano si la belleza languidece melancólica en la modernidad es porque ha sido prisionera del arte autónomo. Sería Warhol (y en general el Pop Art y el Neodadá) quien, con su poética y su obra, habría significado el punto de inflexión al provocar la transferencia de las formas del arte a la vida que habría quedado 
infructuoso en las vanguardias. Supone el final de la estética como filosofía del arte autónomo. Tras la in-formalización llevada a cabo por las experiencias de las lógicas expresionistas y como colofón la abstracta norteamericana, la provocación del Warhol se convierte finalmente en la vía posible de re-mitologización del mundo, abriendo el camino de la nueva era de la globalización y suponiendo la cancelación del siglo $X X$, en la medida en que "Las nuevas divinidades mitológicas de Warhol están lejos de toda contracción idiosincrática, ajenas a toda profundidad psicológica: en su reiterativo presentarse, adornan el mundo" (Vercellone 2013, 195). La liberación del arte del mundo del arte, un arte que abandona los círculos cerrados de sus instituciones (museos, galerías, curadurías, academias...) y se haga comunitario, se expanda adornando con sus formas el mundo. En una lectura contraria a Danto, Warhol no representa para Vercellone la oportunidad de la semiotización del arte, sino de una nueva simbolización de la belleza. Si para Danto la belleza primera (la natural) es la determinante contra Hegel (pero admitiéndola, no obstante, como significación funcional en el arte después del final del arte, el cual fue decretado por el propio Hegel), para Vercellone la belleza de la naturaleza segunda (la del arte) es la determinante, como en Hegel, en la medida en que ésta engloba la primera naturaleza, entendida como tecnépoietica, tal como la filosofía presocrática a partir de Demócrito estableció el paradigma de natura laborans (Carchia 2002, 4142), pero permite (contra Hegel ahora) invertir su transcurso teleológicoal abrir la vía del nostos al saber técnico moderno que había sido escindido artificialmente en su olvido del origen en los inicios de la modernidad: su reencuentro goethiano con la morfología primordial. De ahí la fealdad del mundo, según Vercellone, de la implantación o la morfologización artificial del ambiente, del hábitat humano, de esa escisión, en definitiva, del arte estético esterilizado en el circuito cerrado que encapsula la belleza en un pasado remoto e inaccesible (melancólica) y la técnica científica volcada hacia el futuro gobernada por una Razón sin memoria. En suma, dos ámbitos autónomos con fines en sí mismos y vueltos de espaldas uno a otro. De ahí igualmente que Vercellone sólo pueda concebir la eficaciade la belleza simbólica en el mundo, en cuanto valor esencial, disolviendo el arte autónomo: "[...] la eficacia del arte en el mundo, más allá de la condena kantiana a su inefectividad, de la que, en realidad, ha surgido su esterilización en el circuito cerrado —eficaz y potente a su manera, por otra parte- del mercado del arte" (Vercellone 2013, 201). En tanto que para Danto la belleza, en cuanto valor esencial de la vida natural, debe quedar reducida a una parte circunstancial del arte autónomo para poder legitimar la libertad sus lenguajes.

El problema, en última instancia, que plantea la legitimación de la imagen artística, de la obra de arte, en Danto respecto de su valor es semejante, mutatis mutandis, a la postura de Séneca en la situación filosófica en el mundo de la cultura antigua respecto al valor intrínseco del contenido de la de las imágenes bajo el estoicismo ciceroniano, que señalara Panofsky (Panofsky 2016, 23-25). La solución de Séneca suponía la indiferencia del contenido de la imagen, su mera contingencia. Análogamente, la teoría de Danto conduce a una identificación/determinación lógica de la obra de arte, pero a costa de una indiferenciación de su valor intrínseco que sólo vendrá dado contingentemente desde del exterior. En nuestro mundo actual vemos que ello se produce por los círculos del arte al servicio del mercado. Así, llegados a este punto resulta que todo el esfuerzo crítico de lectura del objeto-imagen para legitimar su artisticidad, determinarlos como una obra de arte, no redunda paradójicamente en una valoración intrínseca de la supuesta obra frente a otros productos, sino que, en la praxis de una sociedad capitalista de consumo globalizado, dicho valor se transfiere automáticamente en la apertura de disposición para su convertibilidad en valor (extrínseco) en una burbuja financiera (autónoma) del mercado: el mundo del arte. Por supuesto no se trata de la intención Danto que, además seguramente, éste no es para él un problema propiamente filosófico. En cualquier caso, ello no quiere decir que no se percate de las consecuencias políticas, ya que la belleza como elemento expresivo adecuado en la obra de arte ante la perpetración de la barbarie es sin duda una respuesta política. Desde el punto de vista de la praxis, no deja de llamar la atención que la realización de la obra de arte bella esté circunscrita al arte público monumental 
(memoriales elegíacos), porque aquí coincide con la apuesta de Vercellone.

Según el filósofo italiano, la tecnología sin nostos, es decir sin pasado, se manifiesta en lugares públicos indiferenciados, aeropuertos, estaciones, autopistas, los lugares, o no lugares, según refiere a Marc Augé (Augé 1993) que implican el extrañamiento (de un fluir sin referencia como el de los capiteles que impiden toda identificación, añadiría yo), de igual manera que en la alienación de las periferias urbanas. Lugares construidos bajo la racionalidad arquitectónica según el imperativo del funcionalismo obtuso (autorreferencial: la multiplicación del capital, especificaría yo). Así, frente a la barbarie de la tecnología (una tecnología de la "segunda naturaleza" que permite la destrucción masiva, solamente reservada anteriormente a las catástrofes de la "primera naturaleza") "[...] que, inevitablemente, desemboca en la degradación y la anarquía del abandono" y concluye: "[...] un poco de belleza no haría ningún daño." (Vercellone 2013, 202), parece suplicar a las corrientes neo-vanguardistas. La respuesta, al fin y al cabo, está en la misma lógicamutatis mutandis que la de Danto: la monumentalización de esos espacios, una llamada al ornamento como paliativo o redención de la tecnología funcionalista devastadora. La belleza como ornamento bajo la categoría del decoro: la adecuación de la conducta en el encuentro con el lugar construido. La re-significación arquitectónica del arte público a través del ornamento implicaría la humanización (el reencuentro de la primera y segunda naturaleza) en las actividades funcionales, burocráticas, piadosas, etc., que se desarrollan en esos edificios. $Y$ resulta verdaderamente significativo lo contradictoriamente ingenuo del razonamiento cuando concluye así el párrafo donde explica su argumentación: "[...] el individuo es simplemente "acompañado» por el contexto monumental, el cual ofrece la escena y dictamina el tono de los comportamientos que se desarrollan en su interior. Por lo menos cuando uno de esos lugares desempeña su función y no alberga, por ejemplo, una visita turística, estos no son objeto de la conciencia estética." (Vercellone 2013, 203). ¡Como si el turismo no fuera hoy una función práctica y utilitaria más que viene a colmar la industria del ocio!
En el fondo, se sitúa bajo el paradigma del embellecimiento como un eco tardío de los lamentos de un Ruskin, contra el que justamente protesta Danto. Y como tal, no se sustrae a la gran aporía que ha acompañado la utopía estética en su resolución en la modernidad desde Schiller hasta el surrealismo: o esteticismo político o politización de la estética. Lo cual se pone plenamente de manifiesto al ligar la apuesta por el ornamento en la obra pública a la reivindicación de un nuevo clasicismo. "Se trata de dar un paso más allá y aprovechar la cuestión, en toda su magnitud, así como el desafío que esta plantea. La propuesta —en una primera aproximaciónsería entonces la de una nueva concepción de lo clásico, que no tema tener a la segunda naturaleza (en lugar de la primera) como su fundamento" (Vercellone 2013, 204). Justamente el programa del Movimiento Moderno. En definitiva, la propuesta, paradójicamente, para un programa que pretende deshacerse del arte autónomo, llega a la formulación de la estetización del Movimiento Moderno (en lo que parece ser, por lo demás, una lectura reductiva de Adolf Loos respecto del estatuto del ornamento en el seno del debate de fin de siglo, un complejo tema que aquí no podemos desarrollar).

Sea como fuere, frente a Danto, Vercellone aparece aquí bajo la exhortación de Dostoievski: la belleza salvará el mundo. Un proyecto que, paralela e independientemente a la idea curatorial a la que se refería Danto, hoy acentúa su presencia no sólo en el debate puramente filosófico o teórico-crítico del arte, sino en el amplio sentido estético que implica lo social, político y ecológico.

La simplificación de la declaración dostoievskiana como lema continuista del utopismo estético, que desemboca indefectiblemente en diferentes géneros de esteticismo, requiere prestar atención a algunas reflexiones que problematizan dicho dictamen. Así, desde una filosofía crítica del nihilismo contemporáneo, Stefano Zecchi denuncia el anti-humanismo radical de la mundialización de la tecnología que ha derivado en la indiferenciación de todo valor cultural, y por tanto del arte, en la circulación que homologa los diferentes niveles de los discursos o textos, desmaterializándolos en lo virtual del parámetro técnico-comunicativo. La expresión más lacerante 
vendría puesta de manifiesto en la fealdad del mundo que alcanza su punto culminante (coincidiendo aquí con Vercellone) en los extrarradios de las grandes ciudades:

La désolation d'une banlieue métropolitaine espace du désastre urbain dans lequel on repousse les pauvres, les marginaux, les épaves de la société de consommation - correspond à I'obligation de vivre dans la laideur et, conséquemment, dans la vulgarité et la violence. On veut s'écarter de la laideur, on ne l'aime pas: on comprend alors l'agressivité de celui qui veut la détruire ou le sens de frustration de celui qui se soumet à sa violence (Zecchi 2002, 46-47).

Lejos de una reclamación de un arte público regenerador a través de un restablecimiento crítico del clasicismo, la cuestión planteada por Zecchi trasciende la idea de una legitimación de la belleza en el arte público, podríamos decir. Más bien apela a la revocación del fundamento nihilista que ha aquilatado la modernidad desde un pensamiento que devuelva la dimensión de lo simbólico a lo imaginario. Se trata de repensar la belleza como categoría estética en su trama histórica desde la Antigüedad, e incluso extendiéndola a tramas no occidentales, que redimensione la belleza para desde ahí poder analizar cuál puede ser su funcionalidad en el mundo y su relación, vinculante o no, con el arte de las sociedades tardocapitalistas.

Esta constituye la voluntad de las investigaciones de François Jullien, acudiendo al pensamiento de la tradición china, para salir del impasse en que nos hallamos como resultado de la ofensiva del arte contemporáneo sobre lo bello que vierte la constante amenaza de la liquidación del arte mismo. Paradójicamente, señala con agudeza, cuando el arte (occidental) expulsa lo bello, la categoría para la experiencia de lo estético se ha mundializado a partir de la teorización de la cultura occidental, de manera que "L'ironie de l'Historie est que, au moment précis où elle s'est mise à imploser, la catégorie du beau a fini d'uniformément s'imposer" (Jullien 210, 214). La consecuencia en Oriente (China, Japón...), y se podría extender a cualquier parte del globo, es que el arte confiado a esta categoría se ha vuelto ilegible para sí mismo y conjuntamente ha contribuido más a constituirse en barrera entre culturas que en posibilidad de participación. La asunción además del arte contemporáneo globalizado destructor de la belleza, ahondaría aún más la distancia de su propia tradición artística, a cambio participa plenamente en el conjunto del intercambio cultural en el marco global de los mercados financieros. En definitiva, señala que la universalización de lo bello se ha llevado a cabo a costa de su devaluación categorial, de su simplificación en su traslación lingüística a otras tradiciones culturales, en un concepto tan insustancial como el Kitsch. El arte contemporáneo que rechaza lo bello, lo hace teniéndolo como referencia en su doble vertiente, por un lado como lo meramente placentero, por otro como profecía de salvación o su variante atenuada, la compensación. Devolver lo bello a su extrañeza es la vía de Jullien, devolver lo bello a su carácter inventivo, la cuestión radical: investigar las condiciones de posibilidad de lo bello, en el sentido de una nietzscheana genealogía (Jullien 2010, 211213), dónde pueda confluir las contribuciones de otras tradiciones culturales.

Es una línea conforme, entonces, a la que plantea Franco Rella frente a las lecturas simplistas del culto a la belleza, en que lo pertinente es preguntarse, pero qué belleza (Rella 2017, 9). No ciertamente el insípido ideal de lo bello, ni mucho menos el hedonismo consolador, sino aquélla que nos sitúa ante el enigma de la diferencia (Rella 1991), que indaga en el origen mito-poético de la ambivalencia de diosa Afrodita (Carchia 2002, 9-10). Venecia es bella porque lleva en sí la destrucción, es la extrañeza de algo que cautiva y espanta, nos dice Jullien (Jullien 2010, 88 y 216), porque los sucios y villanos inmuebles de ciertas construcciones prefiguran su muerte. Por eso Thomas Mann no escribió un mero relato, sino una teoría de lo bello y del amor, que nos cautiva y nos devora, del destino del hombre.

Es aquí justo dónde se invierte adecuadamente la fórmula de Dostoievski: el mundo salvará la belleza. Así reza el título de un opúsculo del historiador del arte Salvatore Settis. En su caso, la conciencia patrimonial detecta perfectamente desde el punto de vista de la tutela que la muerte de Venecia no es su destrucción material exactamente sino el sometimiento al imperativo de su belleza, de la destrucción por la fagocitación 
del turismo de masas al servicio del incremento infinito del PIB que sólo es posible precisamente porque Venecia es bella. Pero qué belleza. La misma que hace destruir la naturaleza al servicio de la belleza, esa que esquilmamos en búsqueda de materias primas para poder viajar en cruceros que ahogan las ciudades patrimoniales portuarias, por ejemplo, esa que invade costas porque son bellas, como Mallorca. Esa belleza en suma que sólo es bella, que como bien dice Rella "[... I' arte solo bella è dunque I'assenza della vera belleza, di quella verità che in qualche modo la deve attraversare" (Rella 2017, 24). Por ello, advierte bien Settis que "[...] la bellezza non salverà il mondo se noi non salviamo la bellezza" (Settis 2015, 19). El ejercicio de la tutela es una cuestión ética, que abarca hoy día a la par la belleza natural y artística en un todo indisoluble. La apuesta hoy no puede ser otra que ecológica, en el sentido de que la destrucción de la naturaleza no es sino la destrucción de ser humano como especie. Sin la ética ecológica el arte es solo bello: un objeto más de consumo, mera mercancía. Y el arte contemporáneo que hoy se legitima frente a la belleza, no lo hace frente a la belleza kitsch, sino paradójicamente frente a la belleza ecológica a la que debemos salvar, porque no es sino el reverso del objeto mercancía: el arte virtual financiero que promueve todo el arte Kitsch. Ambos se necesitan en la lógica implacable.

Así lo entiende Byung-Chul Han cuando analiza la sociedad de lo pulido, lo terso que rige el régimen estético de nuestras sociedades posmodernas. Una estética que aúna en su experiencia perceptiva los diseños de la moderna tecnología con las obras de arte contemporáneo como las de Jeff Koons (Han 2016). La coartada de la ironía, categoría crítica de la que ha abusado la crítica estética hasta la saciedad y la nimiedad, no basta para legitimar esa obra como arte. Precisamente, una de las urgencias del pensamiento estético hoy es elaborar una genealogía de la obra de arte tal como es esbozada por Giorgio Agamben. Porque no está nada claro que se sepa a qué nos referimos con la expresión obra de arte (Agamben 2017, 11). En el mundo de las creaciones como arte contemporáneo, las obras de arte bellas como las de Jeff Koons son el correlato exacto de las no-obras de los performances o las obras repugnantes y abyectas de Damien Hirst.
Lo que las une es que ambas se venden en el proceloso mercado del arte que no es nada irónico. La cuestión es por qué seguimos llamándoles con la noción arte, es una cuestión lógica o es una cuestión de valor, de legitimación ética y estética. Preguntarse por la belleza hoy es cuestionar el valor del arte. Porque la cuestión que debe ser tarea en el seno de una estética sociológica auxiliada por la historia social del arte es por qué las sociedades que paulatinamente abandonaron el culto de lo sagrado desde el Renacimiento fueron elaborando el concepto de arte bello, que sólo fue autónomo desde la llustración. A qué estrategia obedece esa autonomía que llegados los movimientos vanguardistas provocan la escisión de lo estético y lo artístico. Por qué, en definitiva, en la modernidad a medida que la belleza es despreciada, injuriada, por el arte, justamente lo bello no deja de ser un valor sino que se eleva en culto del modo de vida. Por qué lo bello degradado por el arte de vanguardia no se ha transferido como valor a la vida social, sino que es recogido como escombro y encumbrado a panacea en los ideales de las sociedades nihilistas de consumo. Por qué la búsqueda de la belleza otorgada como tarea al arte ha sido transferida al individuo narcisista como canon de éxito, de promesa de felicidad, para recoger el lema de Stendhal tan en boga hoy también. Por qué, como dice Byung-Chul Han, la belleza se ha vuelto, en el arte o no, pornográfica, para su consumo inmediato.

Porque la belleza tiene ese componente enigmático con lo erótico que no es sino el fundamento mismo de la vida. Las sociedades hoy que han abjurado de lo utópico, del diseño estético en el sentido de Giulio Carlo Argan (Argan 2010), que han abandonado los ideales de un perfeccionamiento ético y, por ende, comunitario lo declinan en el individuo particular, se vuelve estético, sólo estético. Ya que ser más perfectible moralmente es totalmente inútil me vuelco en mi perfeccionamiento estético que pone a mi alcance toda la industria del progreso tecnológico en cosmética y cirugía. El progreso que no puede hacernos seres más éticos puede en cambio hacernos más hermosos, más atractivos, más pornográficos. La belleza es promesa de felicidad estética, nos hará más consumidores y más consumibles. Sin embargo, la idea de Stendhal de la belleza como promesa de felicidad no es 
tanto la salvación del mundo, sino que plantea un destino del hombre, como además prueba que Nietzsche (Nietzsche 1996, 120121) aludiera a esta fórmula de Stendhal frente al Kant del hedonismo emasculado, relacionándolo con el mito de Pigmalion. La cuestión, finalmente, responde a la duda que asalta a cualquiera que se siente atraído por la belleza ajena, qué grandeza, qué felicidad, si además fuera ético... porque también te puede conducir al abismo. El arte no ha hecho más que plantear este interrogante en el desafío del destino humano. La crítica de arte que no se ampare en unas categorías estéticas, la belleza principalmente, con un arduo trabajo de interpretación para el momento histórico que vivimos no hace más que hacerse partícipe del nihilismo que invade nuestro mundo. 
Belleza y legitimación del arte contemporáneo

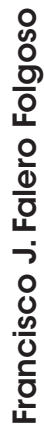

\section{NOTAS}

1 En concreto se refiere al sentido de "abuso" otorgado a la palabra francesa injuriée, siguiendo la norma de la traducción en inglés "to abuse", en vez de por injuriada como es canónico en las traducciones españolas.

2 "Y es prueba de esto lo que sucede en la práctica; pues hay seres cuyo aspecto real nos molesta, pero nos gusta ver su imagen ejecutada con la mayor fidelidad posible, por ejemplo, figuras de los animales más repugnantes y de cadáveres" (Aristóteles, 1974136). 


\section{REFERENCIAS}

Adorno, Theodor. Teoría estética. Madrid: Taurus, 1980.

Aristóteles. Poética, Editado por Valentín García Yebra. Madrid: Gredos, 1974.

Agamben, Giorgio. "Archeologia dell'opera d'arte." In Arte e anarchia. L'opera nell'età della religione capitalista, 7-28. Venecia: Neri Pozza, 2017.

Argan, Guilio Carlo. Lo artístico y lo estético. Madrid: Casimiro, 2010.

Augé, Marc. Los no lugares, espacios del anonimato. Una antropología de la sobremodernidad. Barcelona: Gedisa, 1993.

Badiou, Alain. Petit manuel d'inesthétique. Paris: Seuil, 1998.

Carchia, Gianni. L'estetica antica. Bolonia: II Mulino, 2002.

Clair, Jean. Considérations sur l'état de beauxarts. Critique de la modernité. Paris: Gallimard, 1983.

Danto, Arthur C. La transfiguración del lugar común: una filosofía del arte. Barcelona, Paidós, 2002.

Danto, Arthur C. El abuso de la belleza. La estética y el concepto de arte. Barcelona: Paidós, 2005.

Ferry, Luc. Le sens du Beau. Aux les origines de la culture contemporaine. Paris: Le Livre de Poche, 2017.

Gadamer, Hans-Georg. La actualidad de lo bello. Barcelona: Paidós, 1991.

Griffero, Tonnino. "Storia dell'estetica moderna." In Estetica, categorie, bibliografia, editato por Sergio Givone, 1-128. Florencia: La Nouva Italia, 1998.

Han, Byung-Chul. La salvación de lo bello. BarceIona: Herder, 2016.

Heinich, Natalie. Le Triple Jeu de l'art contemporain. Sociologie des arts plastiques. Paris: Minuit, 1998.

Hickey, Dave. The Invisible Dragon. Essays on Beauty. Chicago: University of Chicago Press, 2012.
Jullien, François. Cette étrange idée du beau. Paris: Grasset, 2010.

Kacem, Mehdi Belhaj.2010. Inesthétique et mimesis. Badiou, Lacou-Labarthe et la question de l'art. Fécamp: Lignes.

Kant, Immanuel. Crítica del Juicio. Ed. Manuel García Morente. Madrid: Espasa-Calpe, 1990.

Liessmann, Konrad Paul. Filosofía del arte moderno. Barcelona: Herder, 2006.

Marquard, Odo. Estetica ed Anestetica. Bolonia: II Mulino, 1994.

Menna, Filiberto. Profezia di una società estetica. Saggio sull'avanguardia artistica e sul movimento dell'architettura moderna. Milán: Editoriale Modo, 2001.

Michaud, Ives. La crise de l'art contemporain. Utopie, démocratie et comédie. Paris: Presses Universitaires de France, 2015.

Newman, Barnett. "Lo sublime es ahora." In Escritos escogidos y entrevistas, 214-218. Madrid: Síntesis, 2006.

Nietzsche, Friedrich. La genealogía de moral: un escrito polémico. Madrid: Alianza, 1996.

Panofsky, Erwin. Idea. Contribución a la historia de la teoría del arte. Madrid: Cátedra, 1989.

Plebe, Armando. "Origini i problemi dell'estetica antica." In AAVV. Momenti e problemi dell'estetica. Vol. I, Dall'antichità classica al barocco. Milán: Marzorati, 1979.

Rella, Franco. L'enigma della bellezza. Milán: Feltrinelli, 1991.

Rella, Franco. Quale bellezza? Nápoles: Orthotes, 2017.

Schaeffer, Jean-Marie. L'art de l'âge moderne: l'esthétique et la philosophie de l'art du XVIIIe siècle à nos jours. Paris: Gallimard, 1992.

Schaeffer, Jean-Marie. Adiós a la estética. Madrid: Antonio Machado Libros, 2005.

Settis, Salvatore. II mondo salverà la bellezza? Responsabilità, anima, cittadinanza. Milán: Ponte alle grazie, 2015 .

Vercellone, Federico. Más allá de la belleza. Madrid: Biblioteca Nueva, 2013. 
Belleza y legitimación del arte contemporáneo

o Winckelmann, Johann J.Historia del Arte en la

Généalogie critique et axiomatique minimale. Antigüedad. Madrid: Akal, 2011.

Actes du colloque international-Université Paris

Zecchi, Stefano. "La beauté moderne existe-t-elle?" VII - Université de Venise, edited by Ciro GiordaIn Utopia 3. La question de l'art au $3^{e}$ millénaire. ni Bruni, 41-47. Paris: GEMRS, 2002. 